\title{
Improving the Experience of Hospitalization for Hawaiian Children on the Mainland Through Cultural Sensitivity to Hawaiian Ways of Healing
}

Jane H. Lassetter

Brigham Young University - Provo, jane_lassetter@byu.edu

Joan H. Baldwin

Brigham Young University - Provo

Follow this and additional works at: https://scholarsarchive.byu.edu/facpub

Part of the Other Nursing Commons, and the Pediatric Nursing Commons

\section{Original Publication Citation}

Lassetter, J. H., \& Baldwin, J. H. (2005). Improving the experience of hospitalization for Hawaiian children on the mainland through cultural sensitivity to Hawaiian ways of healing. Journal of Pediatric Nursing, 20(3), 170-176.

\section{BYU ScholarsArchive Citation}

Lassetter, Jane H. and Baldwin, Joan H., "Improving the Experience of Hospitalization for Hawaiian Children on the Mainland Through Cultural Sensitivity to Hawaiian Ways of Healing" (2005). Faculty Publications. 5178.

https://scholarsarchive.byu.edu/facpub/5178

This Peer-Reviewed Article is brought to you for free and open access by BYU ScholarsArchive. It has been accepted for inclusion in Faculty Publications by an authorized administrator of BYU ScholarsArchive. For more information, please contact ellen_amatangelo@byu.edu. 


\title{
G Improving the Experience of Hospitalization for Hawaiian Children on the Mainland Through Cultural Sensitivity to Hawaiian Ways of Healing
}

\author{
Jane H. Lassetter, MSN, RN \\ Joan H. Baldwin, DNSc, RN, HNC
}

\begin{abstract}
The experience of hospitalization for Hawaiian children on the mainland might be improved through the understanding and development of cultural sensitivity to Hawaiian ways of healing. This article contains a selected review of the literature on meeting the cultural health care needs of Hawaiian children and their families, a discussion of some of the challenges of caring for Hawaiian children in Utah, and suggestions for practice that may improve the experience of hospitalization for Hawaiian children in general.

(C) 2005 Elsevier Inc. All rights reserved.
\end{abstract}

$\mathbf{T}$ HE U.S. DEPARTMENT of Health and Human Services/Bureau of Primary Health Care has proposed that successful health care requires $100 \%$ access and $0 \%$ disparity (Broad \& Allison, 2002). This goal is clearly challenging, especially in light of the rapidly changing demography of the United States.

Sometimes, the demography changes in ways and places that may be surprising. For instance, the 2000 Census revealed that the fastest growing group in Utah is Native Hawaiian and other Pacific Islanders. Between the 1990 and 2000 Censuses, the growth rate of this particular population in Utah was $178.4 \%$, bringing the state's Native Hawaiian and other Pacific Islander population to 21,367 (U.S. Census Bureau, 2001). Only four states (Hawaii, California, Washington, and Texas) had more Native Hawaiians (hereafter Hawaiians) than Utah in 2000 (Utah State Office of Pacific Islander Affairs, 2001). Comparatively, the cost of living in Utah is considerably lower than in Hawaii, which may influence migration. Weiler (2001) found that

From the College of Nursing, Brigham Young University, Provo, UT.

Address correspondence and reprint requests to Jane $H$. Lassetter, MSN, RN, College of Nursing, Brigham Young

University, 424 SWKT, Provo, UT 84602.

E-mail: jane_lassetter@byu.edu 0882-5963/\$-see front matter

(C) 2005 Elsevier Inc. All rights reserved.

doi:10.1016/j.pedn.2005.01.005
Hawaiians come to Utah for various reasons, including family and religious ties.

Making this health-care goal of $100 \%$ access and $0 \%$ disparity of even more importance is that research suggests that Pacific Islanders are considerably less satisfied with health care than other groups in the United States (Haviland, Morales, Reise, \& Hays, 2003). Diminished satisfaction with care may be from lack of comfort while in the health-care arena because of health-care providers' lack of sensitivity to Hawaiian healing traditions, impacting the perception of access for many Hawaiians.

According to Gardenswartz and Rowe (1998), "true healing requires not only the correcting of a disease or the abatement of pain, but also the creation of a condition of wholeness - psychological, physical, and emotional well-being" (p. XVIXVII). For this to be accomplished, the cultural health beliefs and practices of patients and their families should be acknowledged, respected, and integrated into the care that is ultimately provided. By doing so, some barriers to care will be broken down, and the health-care environment can become more comfortable, and, therefore, implicitly more accessible. The purposes of this article are (a) to review the literature on meeting the cultural healthcare needs of one ethnic group, Hawaiian children and their families, (b) to discuss the needs and challenges of Hawaiian children in one mainland state, Utah, and (c) to suggest some implications 
for practice that may improve the experience of hospitalization for Hawaiian children. The concept of cultural health-care needs, as defined in this article, refers not to disease-related disparities, but to ways of healing, including the cultural health beliefs and practices, that are significant to the population of interest.

\section{REVIEW OF THE LITERATURE}

There is a great deal of literature to support the notion that culture has a significant impact on health and health care. From food preferences and behavioral norms to choice of provider (folk healer and/or allopathic or Western health-care provider), health and healing are truly in the eye of the beholder, and the eye is powerfully influenced by the culture(s) of the individual and family. In the vast human family, healing may be accomplished by practices and rituals that include, but are not limited to, dancing, chanting, offering sacrifices to gods, praying, administering special substances topically or orally, journeying to sacred places, and cutting into the body to remove a variety of offending parts. Different cultures embrace some practices more than others and may shun certain practices altogether. For instance, all the bells and whistles of high-technology medicine may not be particularly impressive to someone who believes deeply that healing is a supernatural process, requiring supernatural powers. In addition, the permissible degree of intervention and invasiveness of care is largely impacted by culture. Some patients may refuse surgery because their cultural beliefs stipulate that their bodies need to be whole when they die (Gardenswartz \& Rowe, 1998).

Beliefs regarding illness are also shaped by culture. Some cultures view illness as a spiritual imbalance. Other cultures may see illness as punishment from God for a misdeed or as a reprimand from an angry ancestor. Some consider illness to be the result of abuse or neglect of one's body. Bacterial or viral invasion of the body is still thought to cause illness in still other cultures (Gardenswartz \& Rowe, 1998). The view one holds of the cause of illness can influence willingness to treat the illness. For instance, if a person believes that illness is punishment from God, he may believe that it is necessary to accept the natural outcome of the disease as penance for $\sin$.

Recently, there has been a surge in the literature that explores the cultural health beliefs and practices and associated needs for care of various ethnic groups, especially the Latino and Hispanic populations (Flaherty, 2000; Flores, 2000; Flores, Abreu, Olivar, \& Kastner, 1998; Flores \& Mendoza, 2002; Flores \& Vega, 1998; Guendelman \& Wagner, 2000; Lassetter \& Baldwin, 2004). Gardenswartz and Rowe (1998) even discuss organizations that have benefited financially from building trust through striving to meet the needs of Latinos in their communities. Such literature helps raise awareness of Latino groups specifically and cultural awareness and competencies in general, but much work remains to be done exploring the needs of a variety of ethnic groups in the United States.

\section{Native Hawaiians in Hawaii}

It has been estimated that by 2043 full-blooded Hawaiians will have disappeared completely (Louis, 2001). In 1990, the mortality rate of fullblooded Hawaiians was 2.5 times that of partHawaiians and 4.7 times that of all races in Hawaii (Judd, 1998). Hawaiians suffer disproportionately from breast, stomach, lung, and endometrial cancers. Other conditions that affect Hawaiians at disproportionate rates include obesity, hypertension, diabetes, and cardiovascular disease (Busch, Easa, Grandinetti, Mor, \& Harrigan, 2003). These figures clearly illustrate the existence of disparities among this population, despite a nearly unprecedented level of health-care coverage in the state of Hawaii (Andrade et al., 1994; Bell et al., 2001). Disparity and access issues normally go hand in hand. This combination of information suggests that health-care coverage alone may not be enough to eliminate disparities.

Some authors of recent literature have explored the cultural health beliefs and practices and associated needs for care of Hawaiians in Hawaii. The importance of integrating traditional Hawaiian therapies with allopathic medicine into treatment plans for Hawaiians in Hawaii is highlighted in some literature (Broad \& Allison, 2002; Herrigan, 2000a, 2000b; Mayberry, Affonso, Shibuya, \& Clemmens, 1999).

In the Hawaiian culture, the family unit ('ohana) reflects collectivism and often includes the nuclear family, extended family, and close friends. The role of 'ohana in coping and healing and the importance of mutual support (kokua) in decision-making and care-taking are emphasized in some literature (Braun, Mokuau, Hunt, Kaanoi, \& Gotay, 2002; Braun, Mokuau, \& Tsark, 1997; 
McCubbin, Thompson, Thompson, McCubbin, \& Kaston, 1993). This collectivist view can cause some conflict with the strong individualism of mainstream U.S. culture. Family actions that may be viewed as meddling and interfering by healthcare providers from an individualistic culture are likely to be thought of as loving and supportive by those who come from a collectivistic background (Gardenswartz \& Rowe, 1998), such as the Hawaiian culture.

Although the environment of care is always important, it appears to be of particular significance to Hawaiians, and some methods of meeting these needs have been identified in the literature (Braun et al., 1997; Broad \& Allison, 2002; Herrigan, 2000a, 2000b; Walker \& Irvine, 1997). Specifically, wide hallways, the ability to let the outside air into the hospital room, healing music, and aromatherapies have been incorporated into some hospitals in Hawaii to create a sense of welcome/aloha and contribute to the healing environment in culturally mindful ways (Herrigan, 2000b; Walker \& Irvine, 1997).

Broad and Allison (2002) conducted a quantitative study with patients regarding their health beliefs and practices and the type of provider sought for health-care needs. According to their research, traditional Hawaiian therapies and healthcare providers willing to integrate allopathic and Hawaiian treatments were highly valued by Hawaiians. Braun et al. (2002) conducted a phenomenological study with Hawaiian patients experiencing cancer and obtained rich information about these patients' experiences and suggested cultural interventions to improve care for this group of patients.

\section{Hawaiian Children}

Literature on the cultural needs of Hawaiian children in a health-care setting was quite limited. For example, one article was located in which the authors addressed the impact of Hawaiian culture on how families adapt to having disabled or chronically ill children (McCubbin et al., 1993). In another article, Mayberry et al. (1999) discussed the use of traditional Hawaiian therapies in caring for Hawaiian newborns and adolescent mothers as components of their broader program of pregnancy and postpartum care.

In a large cross-sectional study involving Hawaiian and non-Hawaiian adolescents in the high school setting, researchers with the Native Hawaiian Mental Health Research Development Program
(NHMHRDP) found that more Hawaiian adolescents (278) would prefer to receive treatment from Hawaiian healers than those who actually received care from Hawaiian healers (220) (Andrade et al., 1994). In addition, Bell et al. (2001) reported that $33.8 \%$ of Hawaiian adolescents preferred Hawaiian healers compared with only $8.6 \%$ of non-Hawaiian adolescents. This difference was significant $(p<$ $.0001)$. Many respondents (21.3\%) did not answer the forced-choice response on provider preference, suggesting that limiting the choice to just one type of provider was uncomfortable and that a combination of Hawaiian healers and allopathic providers may have been appealing (Andrade et al., 1994). No research was located that specifically examined the cultural health beliefs and practices and associated needs for care among hospitalized Hawaiian children and their parents in Hawaii or on the mainland.

\section{HAWAIIANS IN UTAH}

The first Hawaiians came to Utah in 1889, and the influences of their culture have impacted Utah ever since. Hawaiians have continued moving to Utah for educational opportunities and religious and family ties (Weiler, 2001).

No published literature was located that examined the health-care need of Hawaiians in Utah. However, a recent environmental scan examined the needs of Hawaiians in Utah. An environmental scan includes observation and searching local information regarding a specific population and needs. Themes that emerged from the environmental scan included (1) the significance of cultural pride, (2) the struggle of straddling two cultures, and (3) a need for integration of Hawaiian cultural health beliefs and practices into health care for Hawaiian children (Lassetter, 2003).

\section{Cultural Pride}

There is a sense of great pride about being Hawaiian in Utah. An example of an expression of cultural pride is the annual 3-day event around Memorial Day. Hundreds of Pacific Islanders gather in Iosepa, the first settlement of Hawaiians in Utah, to remember their cultural heritage and to enjoy a sense of unity. In addition, there is a desire to teach their neighboring Utahans about the Hawaiian culture. The spirit of aloha is the foundation of the culture. It is giving and peaceful and often expressed through music. Various groups perform the music and dance of the Hawaiian 
Islands at a variety of functions throughout the community (Weiler, 2001).

\section{Straddling Two Cultures}

The concept of straddling two cultures is defined in this article as attempting to incorporate the values, beliefs, and practices of mainstream culture while simultaneously retaining one's ethnic cultural values, beliefs, and practices. Being Hawaiian and living in Utah does appear to elicit the challenges of straddling two cultures. Those who were born in Hawaii and live in Utah experience a constantly evolving identity, but their foundations are firmly rooted in the culture of the islands. In addition, Hawaiian children, who are born in Utah, no matter how traditionally they are raised at home, have a much different worldview than their parents (Weiler, 2001). There is a strong desire among young Hawaiians living in Utah to fit in with the mainstream culture. Young Hawaiians have some trouble navigating their two value systems: (1) one from the islands where extended families help to rear children and children obey without question and (2) an American value that children speak freely and negotiate their own space (Weiler, 2001).

A specific example to illustrate the struggle that can arise from endeavoring to span the two value systems is that according to Hawaiian culture, it is disrespectful for a child to look an adult in the eye. Making eye contact is commonplace in mainstream American culture, and failure to do so may suggest a lack of honesty to mainstream Americans. These contrasting cultural beliefs make it difficult for a child, who has been raised in Utah and in a family rooted in Hawaiian culture, to know how to behave in numerous situations (Weiler, 2001).

There are other differences between Hawaiian and mainstream American cultures that may contribute to the struggle of Hawaiian children who find themselves in the middle of these two ways of life. Hawaiian culture is very communal and collectivistic, which suggests involving many family members in decision-making related to health care (Ishida, Toomata-Mayer, \& Mayer, 1996). This could potentially be awkward for children and teens with inclinations to be more individualistic than their family's culture (Gardenswartz \& Rowe, 1998). Additionally, Hawaiian ways of healing include massage therapies and herbal remedies. A child or teen may feel a need to choose between Hawaiian ways of healing and allopathic remedies (Andrade et al., 1994). Nurses and other health-care providers can facilitate integration of different modes of healing, thereby helping the child feel comfortable incorporating both viewpoints into care.

\section{Need for Integration of Cultural Health Beliefs and Practices into Care}

People learn a good deal from their cultural and ethnic background about how to be healthy, how to recognize illness, how to be ill, and how to respond to illness. Cultural backgrounds also impact how patients access and respond to health-care services (Spector, 2004). In addition, there is a tendency, in the face of an illness crisis, for people to return to their cultural roots for guidance. Cultural health beliefs and practice are portable and do not remain behind when an individual or family moves to a new location. Therefore, the findings in the study by researchers with NHMHRDP discussed earlier likely apply to Hawaiian adolescents in Utah and other places. It is certainly possible that a substantial portion of Hawaiian adolescents, who have migrated to Utah and have with families who believe in and practice traditional healing ways, may prefer care from Hawaiian healers or collaborative care between allopathic providers and Hawaiian healers. This may be the case whether the family migrated in recent years or a generation or two ago and have retained their cultural beliefs.

Enhancing the environment of healing within hospitals in ways that are culturally appropriate to more than just the mainstream American culture as discussed by Broad and Allison (2002), Herrigan (2000b), and Walker and Irvine (1997) could help increase the comfort level of Hawaiian pediatric patients and pediatric patients from a variety of cultural backgrounds. The need for enhanced sensitivity to cultural ways of healing may be more evident in locations, such as Utah, that historically have had little diversity. With the changing demography, culturally appropriate environments of care need to be considered to increase the comfort level of an ever-widening variety of patients, thus impacting access to care.

\section{IMPLICATIONS FOR PRACTICE}

Recent research has provided some insights about Hawaiian cultural health beliefs and practices, but there is much still to learn. Inasmuch as the voices of Hawaiian children experiencing hospitalization and their parents have not been heard in the literature, there is little knowledge about what that experience is like for them. There is clearly a 
need for such research to be done. In the meantime, however, there are some things that can be done to help Hawaiian children and their families feel more comfortable during hospitalization.

The three themes identified previously (cultural pride, the struggle of straddling two cultures, and a need for integration of Hawaiian cultural health beliefs and practices into health care for Hawaiian children) have blurred boundaries when it comes to implications for practice. Therefore, implications will be discussed as a whole. There are several similarities between Hawaiian and other collectivistic cultures, such as Native American culture. Thus, recommendations provided in this article may also apply to caring for patients and families from other collectivistic cultures.

Although it may be impractical for mainland hospitals to be rebuilt with wider hallways to increase the cultural comfort level of Hawaiian patients, there are adjustments that can be made to provide more culturally competent care and support Hawaiian ways of healing. For example, health-care providers could be more cognizant that having extended family ('ohana) nearby assists in healing for many people from collectivistic cultures, including Hawaiians. To accommodate such needs, larger waiting rooms and visiting areas could allow more 'ohana members to accompany patients. It is vital for health-care providers to recognize that decision making may occur as a collective family group effort, and the decision rendered may be based on what is most beneficial for the whole family group. A culturally competent health-care provider may also ask if there are others with whom they would like to confer in making decisions. Providing space for family consultations to occur and demonstrating a sensitive, nonjudgmental attitude toward family decisions are very helpful (Gardenswartz \& Rowe, 1998).

Basically, although it is always important to remember the family in provision of care, the family or 'ohana becomes even more important when a pediatric patient is from a collectivistic culture, such as Hawaiian. These patients should not be considered in isolation from their families. By increasing the comfort of the ohana to act in ways that are culturally appropriate for them, the comfort of the child will also be enhanced, potentially improving healing.

To assist patients who are straddling two cultures, health-care workers can be sensitive to Hawaiian ways of healing by inviting cultural artifacts and providing music reflective of the patient's culture may improve the experience of hospitalization. Cultural artifacts are items that help connect an individual to his/her culture. They can be things that would be familiar to mainstream culture, such as a quilt or carving with special meaning to the individual or family, or items that may seem more exotic, such as amulets, wrist strings, and medicine bags. Perhaps, Hawaiian music playing in the background or aromatherapies used by Hawaiians may assist in healing for some patients and help patients and families feel more valued and welcomed. This could be done on an individual room basis to allow other patients their own cultural practices.

Respectful discussion of cultural remedies or rituals that may help the child heal is also very valuable. Although some ways of healing require a Hawaiian healer, others can be and are done without the presence of a healer. It is important for health-care providers to know what cultural health practices are being used by the family so that care can be collaborative and safe. Culturally competent and respectful environments of care are built by allowing cultural health beliefs and practices whenever possible (Flores, 2000).

Gaining an understanding of some of the cultural norms and struggles faced by Hawaiian children may help health-care providers work more collaboratively and sensitively with this patient group. For instance, a health-care provider that understands the cultural norms regarding eye contact may be less concerned when a Hawaiian child does not make eye contact than a health-care provider without that basic understanding of the culture. Additionally, health-care providers that strive to understand the potential clash between the child's collectivistic family culture and the individualism that may be embraced by the child can possibly help the older child or teen navigate complex decision-making situations involving family mores.

Previously noted researchers (Broad \& Allison, 2002; Herrigan, 2000a, 2000b; Mayberry et al., 1999) have suggested that Hawaiians value the integration of traditional Hawaiian therapies and healers with allopathic medicine into treatment plans, involvement of 'ohana in decision-making and care-taking, and environments of care that are conducive with Hawaiian cultural beliefs and practices. There is a growing population of Hawaiians on the mainland United States, and efforts to meet their cultural health-care needs can 
help improve their satisfaction with health care, access, and, hopefully, their overall health status.

\section{Applications for Other Cultural Groups}

In addressing access and disparity issues, each population deserves individual attention. This article has addressed the some of the basic cultural health-care needs of one population. In assessing the needs of other cultures, it is important to discover how their cultural pride is displayed in the community and to be respectful and supportive of their cultural pride. The local health department and offices of minority affairs can be helpful in learning about the cultural health care of various groups (Leininger, 2001). Often, health departments in major cities have access to appropriately trained interpreters who are cognizant of healthcare terminology and have the ability to be "culture brokers" as well. In other words, these interpreters can help pinpoint the cultural sensitivities that need to be addressed.

Local universities can be a great resource through foreign language departments and may include resource librarians, who can guide exploration of various cultures. Coworkers, neighbors, friends, or acquaintances from the ethnic group of interest can be valuable culture brokers in improving cultural competence related to specific groups (Leininger, 2001). However, caution should be exercised by not assuming that membership in the cultural group in question means that there is automatically understanding of the health-care ramifications of every situation. At times, members of the cultural group, who may be asked to interpret, are not fully aware of specific healthcare needs and may misunderstand or misinterpret, thus causing mixed messages to occur.

Finally, the World Wide Web offers many resources. As examples, the World Health Organization Internet site (http://www.who.int/en/) and the American Public Health Association Internet site (http://www.apha.org) have a wealth of information and are worth exploring to help determine needs of specific populations (Leininger, 2001).

\section{CONCLUSION}

The authors of this article have reviewed the literature on meeting the cultural health-care needs of Hawaiian children and their families, discussed the needs and challenges of Hawaiian children in Utah, and suggested some implications for practice that may improve the experience of hospitalization for Hawaiian children. Although there is still much to learn in this area, the information contained in this article, if applied, may help increase the comfort level of Hawaiian children and their families experiencing hospitalization. By so doing, their access to care is likely to be enhanced.

In our ever more diversifying world, communities, and hospitals, the need for cultural sensitivity and competence in nursing becomes more important with each passing day. For nurses to do their part in reaching goal of $100 \%$ access and $0 \%$ disparity set by the U.S. Department of Health and Human Services/Bureau of Primary Health Care, quality efforts to enhance cultural competency and sensitivity need be thoughtful and ongoing.

\section{REFERENCES}

Andrade, N. N., Johnson, R. C., Edman, J., Danko, G. P., Nahulu, L. B., Makini, G. K., et al. (1994). Non-traditional and traditional treatment of Hawaiian and non-Hawaiian adolescents. Hawaiian Medical Journal, 53, 344-347.

Bell, C. K., Goebert, D. A., Andrade, N. N., Johnson, R. C., McDermott, J. F., Hishinuma, E. S., et al. (2001). Sociocultural factors influencing adolescent preference and use of native Hawaiian healers. Complementary Therapies in Medicine, 9, 224-231.

Braun, K. L., Mokuau, N., Hunt, G. H., Kaanoi, M., \& Gotay, C. C. (2002). Supports and obstacles to cancer survival for Hawaii's native people. Cancer Practice, 10, 192-200.

Braun, K. L., Mokuau, N. K., \& Tsark, J. U. (1997). Cultural themes in health, illness, and rehabilitation for Native Hawaiians: Observations of rehabilitation staff and physicians. Topics in Geriatric Rehabilitation, 12, 19-37.

Broad, L. M., \& Allison, D. M. (2002). Nurse practitioners and traditional healers: An alliance of mutual respect in the art and science of health practices. Holistic Nursing Practice, 16, 50-57.

Busch, J., Easa, D., Grandinetti, A., Mor, J., \& Harrigan, R. (2003). Healthy people in Hawaii?: An overview of ethnic health disparities in Hawaii for the Healthy People 2010 initiative targeted health concerns. Hawaii Medical Journal, $62,10-14$.

Flaherty, L. (2000). Report issued on health care of America's children [from the Feds]. Journal of Emergency Nursing, 26, 356-357.

Flores, G. (2000). Culture and the patient-physician relationship: Achieving cultural competency in health care. Journal of Pediatrics, 136, 14-23.

Flores, G., Abreu, M., Olivar, M. A., \& Kastner, B. (1998). Access barriers to health care for Latino children. Archives of Pediatric and Adolescent Medicine, 152, 1119-1125.

Flores, G., \& Mendoza, F. S. (2002). ¿Dolor aqui? iFiebre?: A little knowledge requires caution. Archives of Pediatrics \& Adolescent Medicine, 156, 638-640.

Flores, G., \& Vega, L. R. (1998). Barriers to health care access for Latino children: A review. Family Medicine, 30, 196-205.

Gardenswartz, L., \& Rowe, A. (1998). Managing diversity in health care. San Francisco, CA: Jossey-Bass. 
Guendelman, S., \& Wagner, T. H. (2000). Health service utilization among Latinos and white non-Latinos: Results from a national survey. Journal of Health Care for the Poor and Underserved, 11, 179-194.

Haviland, M. G., Morales, L. S., Reise, S. P., \& Hays, R. D. (2003). Performance measures: Do health care ratings differ by race or ethnicity? Joint Commission Journal on Quality and Safety, 29, 134-145.

Herrigan, B. (2000a). Papa Henry Auwae Po òkele la `au lapa au: Master of Hawaiian medicine. Alternative Therapies, 6, 82-88.

Herrigan, B. (2000b). Earl E. Bakken. Building a healing hospital. Alternative Therapies, 6, 82-88.

Ishida, D. N., Toomata-Mayer, T., \& Mayer, J. F. (1996).

Samoans. In J. G. Lipson, S. L. Dibble, P. A. Minarik (Eds.), Culture and nursing care: A pocket guide (pp. 250-263). San Francisco, CA: UCSF Nursing Press.

Judd, N. L. (1998). Laau, Lapaau: Herbal healing among contemporary Hawaiian healers. Pacific Health Dialog, 5, $239-245$.

Lassetter, J. H. (2003). Exploring the phenomenon of hospitalization for Native Hawaiian children in Utah: A proposal. Unpublished manuscript, Oregon Health and Science University, Portland, OR.

Lassetter, J. H., \& Baldwin, J. H. (2004). Health care barriers for Latino children and provision of culturally competent care. Journal of Pediatric Nursing, 19, 184-192.

Leininger, M. (2001). Transcultural nursing care in the community. In J. H. Baldwin, K. S. Lundy, S. Janes (Eds.), A resource of ideas and teaching strategies to accompany community health nursing: Caring for the public's health (pp. 83 -88). Mississauga, Ontario: Jones and Bartlett.

Louis, K. B. (2001). White paper on the health status of Asian Americans and Pacific Islanders and recommendations for research. Nursing Outlook, 49, 173-178.

Mayberry, L. J., Affonso, D. D., Shibuya, J., \& Clemmens, D. (1999). Integrating cultural values, beliefs, and customs into pregnancy and postpartum care: Lessons learned from a Hawaiian public health nursing project. Journal of Perinatal \& Neonatal Nursing, 13, 15-26.

McCubbin, H. I., Thompson, E. A., Thompson, A. I., McCubbin, M. A., \& Kaston, A. J. (1993). Raising children with disabling conditions in a culturally diverse world: Culture, ethnicity, and the family: Critical factors in childhood chronic illnesses and disabilities. Pediatrics, 9, 1063-1070.

Spector, R. E. (2004). Cultural diversity in health and illness. (6th ed.). Upper Saddle River, NJ: Pearson Prentice Hall.

U.S. Census Bureau. (2001). State and county quickfacts. Retrieved March 20, 2001, from http://www.quickfacts.census. gov/qfd/states/49000.html.

Utah State Office of Pacific Islander Affairs. (2001). U.S. Census 2000: Native Hawaiians \& other Pacific Islanders. Retrieved April 17, 2003, from http://dced.utah.gov/poly/ CENSUS2000pacific-islanders.pdf.

Walker, D. D., \& Irvine, N. P. (1997). Lokomaika i (inner health) in a remarkable hospital. Nursing Management, 28, $33-36$.

Weiler, K. (Executive Producer) (2001, August 28). The Polynesian gift to Utah [Television broadcast]. Salt Lake City, UT: KUED. 